\title{
Fixed Prices and Regulatory Discretion as Triggers for Contingent Capital Conversion: An Experimental Examination*
}

\author{
Douglas Davis ${ }^{\mathrm{a}}$ and Edward Simpson Prescott ${ }^{\mathrm{b}}$ \\ ${ }^{a}$ Virginia Commonwealth University \\ ${ }^{\mathrm{b}}$ Federal Reserve Bank of Cleveland
}

\begin{abstract}
We report a laboratory experiment that evaluates two price-based mechanisms for triggering the conversion of contingent-capital bonds into equity: a regulator who decides based on observed prices and a mechanistic fixed-price trigger. We find that when conversion decreases incumbent equity value, the regulator mechanism generates fewer conversion errors, particularly in environments where incentives bias a regulator against conversion and where a regulator receives his own signal. In contrast, when conversion increases incumbent equity value, a fixed-price trigger generates fewer conversion errors in these environments as well as when the regulator has the option to delay conversion.
\end{abstract}

JEL Codes: C92, G14, G28.

\section{Introduction}

Following the 2008 financial crisis, regulators and banking scholars devoted considerable attention to improving bank capital regulation

${ }^{*}$ We thank the editor Raphael Repullo, an anonymous referee, and Glenn Harrison for helpful comments. We also thank Aaron Lazar for z-Tree programming and assistance with experiment administration. Experiment instructions, experimental data, and a series of unpublished appendixes are available at http://www.ijcb.org. This paper was presented at the Federal Reserve Bank of Atlanta, the University of Virginia, Virginia Commonwealth University, the 2014 meeting of the Southern Economics Association, and the 2015 SAET conference. The usual disclaimer applies. Financial assistance from the National Science Foundation (SES 1426980) is gratefully acknowledged. The views expressed in this paper do not necessarily reflect those of the Federal Reserve Bank of Cleveland or the Federal Reserve System. Corresponding author's e-mail: dddavis@vcu.edu; tel.: (804) 828-7140; fax: (804) 828-9103. 
in order to increase the stability of the banking system. One regulation that has been proposed is to require systemically important banks to issue a new class of "contingent-capital" (CoCo) bonds, which convert to equity when a bank passes a predefined triggering condition. One advantage of these bonds is that in times of financial distress they reduce a bank's debt-overhang problem by raising equity at a predetermined price just when raising equity in the capital markets is most expensive. A second advantage is that they automatically recapitalize a bank, thus reducing the chance of a costly resolution, 1

Critical to the effective implementation of CoCos is the trigger used for converting debt into equity. Existing CoCo bonds use an accounting trigger, such as regulatory capital levels, along with some regulatory discretion. Unfortunately, accounting numbers often lag economic values, so CoCo bonds that are based primarily on an accounting trigger may not convert until it is too late 2 A more promising approach is to use a trigger that incorporates information contained in market prices. Unlike most accounting ratios, market prices incorporate expectations and so are forward looking 3 One such trigger is a mechanistic price-based rule, with conversion occurring automatically whenever a pre-specified threshold, such as the price of a bank's equity shares, is breached (e.g., Calomiris and Herring 2013; Flannery 2009; McDonald 2013; Pennacchi 2011; Pennacchi, Vermaelen, and Wolff 2013; and Raviv 2004). An advantage of this kind of rule is that it is transparent regarding the conditions for and magnitude of a conversion.

Alternatively, regulators may use price information to make conversion decisions. Regulations encourage this since CoCo issues are

\footnotetext{
${ }^{1}$ See Prescott (2012) for a discussion of these and other possible benefits.

${ }^{2}$ The U.S. experience with accounting triggers is not promising. Since 1992, U.S. bank regulators have been required to follow prompt corrective action (PCA) rules. These rules require regulators to force banks to increase capital and to take other preventative actions when regulatory capital ratios are breached. Furthermore, they require regulators to put the bank into receivership when capital is below 2 percent. Nevertheless, despite failed banks having on average positive book capital at time of failure, average losses to the deposit insurance fund from commercial bank failures were about 25 percent of failed bank assets. See Balla, Prescott, and Walter (2015) for details. Possibly related, accounting-based measures can sometimes be manipulated. See Calomiris and Herring (2012).

${ }^{3}$ For a classic example, see Roll (1984).
} 
required to allow some regulatory discretion to qualify for tier 1 or tier 2 capital under the Basel III rules (Avdjiev et al. 2015) 4 And while a regulator-based triggering rule is subject to the potential of forbearance, it has the advantage of allowing regulators to incorporate the additional information that they gather from their supervision of the bank. Relative to a mechanistic trigger, however, it creates uncertainty about how the regulator will interpret and react to prices.

Unfortunately, recent theoretical and experimental work has identified costs to using either type of price-based mechanism. Theoretical work on rational expectations models by Birchler and Facchinetti (2007), Bond, Goldstein, and Prescott (2010), and Sundaresan and Wang (2015) show that both fixed-trigger and regulator-based mechanisms are subject to equilibrium nonexistence and multiple equilibria 5 Experimental work by Davis, Korenok, and Prescott "DKP" (2014) finds that these mechanisms induce variability in prices, misallocations, and conversion errors. Nevertheless, accounting-based alternatives have severe limitations, so while imperfect, price-based triggering mechanisms are worth evaluating. Furthermore, there may be ways to improve the performance of these mechanisms.

This paper reports an experiment that measures the effects of three changes to the regulatory price-based mechanism studied in DKP. The first is to change the rewards the regulator receives for making conversion decisions. The second is to give the regulator information in addition to market prices. The third is to give the regulator the option of delaying the conversion decision in return for better information in the future. All three changes correspond to realistic features of the regulatory environment. The results of this experiment and the one reported in DKP are then used to evaluate the relative performance of a mechanistic fixed trigger versus a regulator with discretion. We find that the relative desirability of the two classes of mechanisms depends on whether conversion decreases or increases the value of incumbent equity. The regulator usually performs better when the conversion is value decreasing, which is

\footnotetext{
${ }^{4}$ Regulators do currently use market data in their assessment of banks, though not as a formal part of security conversion. See Feldman and Schmidt (2003).

${ }^{5}$ For recent theoretical work on these issues, see Siemroth (2015).
} 
the case most relevant for the recent policy debate. However, the fixed trigger performs better when the conversion is value increasing, which is relevant for some types of CoCo conversions.

\subsection{Literature}

Sundaresan and Wang (2015) studied the rational expectations equilibria of a price-based, fixed-trigger mechanism that converted debt to equity when the price of equity dropped below a trigger. They found that a fixed trigger can undermine the informational content of the prices on which it relies. The way it undermines informational content depends on the conversion rule, which determines whether and by how much a conversion affects incumbent equity values.

A conversion reduces the value of incumbent equity if the bondto-equity exchange rate is sufficiently dilutive. However, a conversion rule can be value increasing to incumbent equity owners if the value of retiring debt outweighs the dilutive effect of increasing the number of equity shares. The effects of triggering mechanisms on both valueincreasing and value-decreasing conversion rules are of interest. Most academic proposals for the design of CoCos advocate implementing a value-decreasing conversion rule as a means of tempering risktaking incentives by bank managers. Furthermore, the proposals for debt that can be "bailed in" often require that equity be written down and debt converted to equity during resolution. As a practical matter, however, value-increasing conversions are common. For example, roughly half of recent or planned CoCo issues specify a value-increasing conversion. 6

In the case of a value-decreasing conversion, Sundaresan and Wang (2015) showed that a fixed trigger creates multiple equilibria for a range of market fundamentals above the trigger price. The intuition driving this result is straightforward. Suppose that traders are risk neutral and have rational expectations, so that the market

${ }^{6}$ Avdjiev et al. (2015) report that 55 percent of CoCo issues between 2009 and March 2015 involve either a partial or complete principal write-down of the CoCo debt. Such bonds represent an extreme case of a value-increasing conversion, because in the event of a conversion, debt is simply retired, with no associated change to existing equity. But more generally, even if conversion dilutes equity - and the trigger is the price of equity - then there are situations in which conversion increases the value of incumbent equity. 
price of equity equals the expected payout for bank equity. For specificity, suppose also that an equity price of $\$ 5.00$ or less triggers a conversion that reduces the value of equity by $\$ 2.00$ per share. Consider now a market fundamental of $\$ 5.50$. If traders believe that there will not be a conversion, then the price is $\$ 5.50$ and no conversion will occur, which is consistent with traders' beliefs. However, if traders believe that conversion will occur, they will all incorporate the value of the conversion into their price and trade equity at $\$ 3.50$ per share. This price is below the trigger, so conversion will occur, which is also consistent with traders' beliefs. Following this reasoning, multiple equilibria exist for fundamental realizations between $\$ 5.00$ and $\$ 7.00$.

In the case of a value-increasing conversion, Sundaresan and Wang (2015) showed that under a fixed-trigger rule there is instead a problem of equilibrium non-existence. The intuition is again straightforward. Using the parameters of the above example, suppose now that in the case of a conversion, the value of equity increases by $\$ 2.00$ per share. Consider in this case how traders with rational expectations would treat a fundamental value of, say, $\$ 3.50$. If they believe conversion will occur, then a share is worth $\$ 5.50$, but that is above the trigger, so conversion will not occur. Conversely, if they believe that conversion will not occur, then a share is worth $\$ 3.50$, but that is below the trigger, so conversion will occur. For such a realization (and for any fundamental realization between $\$ 3.00$ and $\$ 5.00$ ) no equilibrium price exists.

Birchler and Facchinetti (2007) and Bond, Goldstein, and Prescott (2010) studied the rational expectations equilibria of a related model in which traders had information that a regulator did not (such as knowing the market fundamental) and where the regulator used the market price to decide whether to intervene in the bank, along the lines of a CoCo bond conversion. In their models, they did not find multiple equilibria for value-decreasing conversions, but they did find non-existence of equilibria for value-increasing conversions. Furthermore, they found it for a broader range of fundamentals than under fixed-trigger regimes 7

\footnotetext{
${ }^{7}$ The intuition for the value-decreasing case is straightforward. Unlike a fixed trigger, the regulator has the option to convert at any price, so were the price between $\$ 3.00$ and $\$ 5.00$, the regulator would know not to convert because the
} 
These theoretical results raise concerns about how this kind of triggering mechanism will work in practice. Furthermore, data from existing markets provide little guidance. Although issues of CoCotype bonds have increased substantially in the last several years, no instance of a triggering condition being breached has yet occurred 8 Furthermore, all the existing issuances use accounting ratios (sometimes supplemented by regulatory discretion) rather than market prices as the trigger. Given the paucity of empirical data, experimental methods are a particularly useful source of evidence. DKP report an experiment that evaluates the relevance of the predicted imprecisions with price-based triggering mechanisms. They find that in both fixed-trigger and regulator regimes the theoretically predicted problems of multiple equilibria and equilibrium non-existence manifest themselves as variability in realized prices, prices deviating from realized values, resource misallocations, and conversion errors. Further, and contrary to theoretical predictions, in the case of a value-decreasing conversion, errors occurred in the regulator regime as well as in the fixed-trigger regime. As a consequence, for some ranges of fundamentals, frequent conversion errors occur in markets using either rule.

\subsection{Overview}

An important question not decisively addressed by DKP regards the relative performance of the two triggering mechanisms 9

fundamental must exceed $\$ 5.00$. Traders recognize this and incorporate it into their beliefs. For a value-increasing conversion, the non-existence problem arises because the price as a function of the fundamentals has to be non-monotonic, but then for some values of the fundamental the regulator cannot tell from the price whether the fundamental is below or above the $\$ 5.00$ threshold. See Prescott (2012) for a more detailed explanation of the source of these problems as well as those in the fixed-trigger regime.

${ }^{8}$ Avdjiev et al. (2015) report $\$ 280$ billion in CoCo issuances between January 2009 and March 2015. The vast majority of issues were from European banks, but substantial issues were also made by banks in Australia, Brazil, and Russia. Issues differ widely with respect to conversion ratios and triggering conditions, and while no triggering condition has ever been breached, there is considerable concern in the investment community about the lack of standardization in conditions. See, e.g., Hayden (2014).

${ }^{9}$ Observing that the fixed-trigger mechanism was more readily understood by traders and also eliminated uncertainty regarding the regulator's actions, DKP offers some guarded support for the fixed-trigger mechanism. However, 
Furthermore, a variety of features relevant to the environment in which a regulator acts might affect a regulator's performance. In this paper, we study three such variations from the baseline regulatory experiment. The first variation changes the regulator's incentive to act, so that there is a bias away from conversion. This bias may affect not only the regulator's behavior but also what traders expect the regulator will do, and thus the informational content of prices.

The second variation from the baseline environment supplements the regulator's price observations with non-market information. Bank regulators have special legal powers to conduct bank examinations, and via this process they observe information beyond what is reported in financial statements. Several studies report that such examinations do give bank regulators access to some information before the markets 10 While current and accurate information should clearly help a regulator make decisions, timely non-market information is not always available. We model this by showing the regulator the market fundamental with some probability.

Finally, the third variation we study allows the regulator to wait for non-market information before acting. The time between bank examinations suggests this treatment 11 Immediately following an examination, regulators may have better information about

as reviewed below, support for the fixed-trigger mechanism in the DKP experiment is far from unqualified, and in an important respect the regulator regime generated superior results.

${ }^{10}$ The survey in Flannery (1998) discusses the literature on market prices and bank condition. He reports numerous studies that find that market prices contain information that predicts changes in bank condition as measured by bank regulators. However, he also reports on some studies, such as Berger and Davies (1998), that find that regulators also have some information that the market does not have. See also Berger, Davies, and Flannery (2000) and DeYoung et al. (2001). Furthermore, Bond, Goldstein, and Prescott (2010) show that if the regulator is given his own signal drawn from a uniform distribution, the range of fundamentals for which an equilibrium does not exist decreases as the quality of the signal improves.

${ }^{11}$ For all but the largest banks, bank examinations happen at regular intervals, usually annually, and for that reason, regulator information at any particular point in time may be outdated. Furthermore, as Flannery (1998, p. 293) observes, bank examiners are interested in different information than markets; examiners are most concerned with information about default risk, while equity owners are most concerned with information about the value of a bank in non-default states. For this reason, the market may have information that examiners do not have. 
a bank's financial condition than does the market. However, as the time following an examination increases, the quality of nonmarket information deteriorates, making market-based information a valuable source of information until the next examination. The possibility of delaying action until the next bank examination may affect a regulator's willingness to rely on price-based market signals.

We study these questions by reporting an experiment that builds upon DKP in order to evaluate the relative accuracy of fixed-trigger and regulator-based conversion rules. In addition to more systematically analyzing conversion error rates in the thirty-four market sessions previously reported in DKP, we report eighteen new market sessions conducted in variants of a regulator regime that incorporate inaction bias, non-market information, and the opportunity to delay action.

We find that the conversion rule affects the relative accuracy of fixed-price and regulator-based triggering mechanisms. In the case of a value-increasing conversion, results support economists' predisposition toward the use of a fixed trigger: Previously reported fixed-trigger mechanisms are marginally superior to regulator mechanisms. In the case of a value-decreasing conversion, the reverse is true. Furthermore, we find that both inaction bias and non-market information strengthen this result. In the case of a value-increasing conversion the fixed-trigger rule generates fewer conversion errors than a regulator-based regime, while in the case of a value-decreasing conversion the regulator-based regime is superior.

In the delay treatment, however, the fixed-trigger mechanism is generally preferable. In the case of a value-increasing conversion, a fixed-trigger rule is vastly superior to a regulator-based rule, largely because in this case some regulators appear to ignore altogether the informational content of prices. In the case of a value-decreasing conversion, the fixed-trigger and regulator mechanisms are statistically indistinguishable.

On net we conclude that in the case of a value-increasing conversion, a fixed-trigger rule is strongly preferable. In the perhaps more policy-relevant case of a value-decreasing conversion, however, the regulatory mechanism is usually better, though there are some environments where that is not the case. 


\section{Experiment Design and Procedures}

All the market sessions reported in this paper are variants of the common market structure described in subsection 2.1. Subsection 2.2 reviews the relevant results of the DKP experiment. Afterwards, subsections $2.3,2.4$, and 2.5, respectively, describe the regulator bias, non-market information, and delay treatments that are new to this paper.

\subsection{Market Design and General Procedures}

In each session, there is a cohort of ten traders. In sessions with regulatory treatments, there are also three monitors, who correspond to regulators 12 Each session consists of a sequence of twenty to twentyfive trading periods. In each period, each trader is endowed with two perishable asset units and a working capital loan of $\$ 16.00$ that can be used to start buying assets 13 Asset units expire at the end of each period and pay out an amount that is determined by three factors: (i) the market fundamental, (ii) a trader's idiosyncratic valuation of the asset, and (iii) a conversion, if it occurs. For sessions with a regulatory treatment, monitors are motivated to make a decision to "convert" (intervene) if the underlying market fundamental is below $\$ 5.00$. If the selected monitor chooses to convert, all assets either increase in value by $\$ 2.00$ (in the case of a value-increasing conversion) or fall in value by $\$ 2.00$ (in the case of a value-decreasing conversion).

To induce trade, we give the traders different values from holding the asset at the end of the period. Six traders (who are endowed with twelve units in total) value the asset at $\theta$, which is taken from the interval $[\$ 2.00, \$ 8.00]$. We refer to $\theta$ as the market fundamental. The remaining four traders (who are endowed with eight units in total) value the asset at $\theta-\$ 0.60$. A trader knows his own valuation of the asset, but does not know whether it is the high or low valuation.

\footnotetext{
${ }^{12}$ In the experiments, we referred to the people who could make the conversion decision as monitors.

${ }^{13}$ Unless otherwise noted, dollar amounts refer to lab dollars. Subjects' performance was kept track of in terms of lab dollars and then at the end of a session, lab dollars were converted to U.S. dollars to pay the subjects. The conversion ratio is reported at the end of section 2.1.
} 
A trader also knows the aggregate number of high- and low-value units each period, and thus knows that there are more high-value traders than low-value traders. Once shown their asset value for the period, traders are given 110 seconds to buy and sell assets.

Trading follows standard open-book double-auction rules, with traders seeing all bids, offers, and the history of contract prices in the period. Period earnings for each trader are the sum of revenues from asset sales net of asset purchases and the value of assets held at the period's end, or

$$
\text { Payoff }=\sum_{i=1}^{m_{s}} p_{i}-\sum_{j=1}^{n_{b}} p_{j}+(\nu-c) \times\left(n_{b}-m_{s}+2\right),
$$

where $m_{s}$ units are sold at prices $p_{i}, i=\left\{1, \ldots, m_{s}\right\}$, and $n_{b}$ units are bought at prices $p_{j}, j=\left\{1, \ldots, n_{b}\right\}$. On the right side of the equation, $\nu$ is the trader's valuation of holding an asset, and $c \in\{-\$ 2.00, \$ 0.00, \$ 2.00\}$ reflects the effect on the asset value of the conversion decision. Finally, the working capital that traders start with is paid back at the end of the period, so it nets out in (11).

Conversion is determined by the monitors' decisions following the close of trade. Monitors do not observe the market fundamental, but they do see the median price of contracts. Based solely on the observed price, monitors guess the underlying market fundamental and make a conversion decision. Monitors earn $\$ 3.00$ if their guess is within $\$ 0.20$ of the actual $\theta$ for the period, and $\$ 1.00$ if their guess is between $\$ 0.21$ and $\$ 0.50$ of the period's $\theta$. For conversion decisions, monitors earn $\$ 12.00$ from a correct decision, where a "correct" decision is either to convert if the underlying fundamental is less than $\$ 5.00$ or to not convert if the fundamental is $\$ 5.00$ or more. To prevent insurance strategies, monitors are obligated to make a conversion decision consistent with their guess of $\theta$.

Once all monitor decisions are complete, the market fundamental is displayed and earnings are determined. For a monitor, earnings are $\$ 0.00, \$ 1.00, \$ 3.00, \$ 12.00, \$ 13.00$, or $\$ 15.00$, depending on the accuracy of his guess about the fundamental and whether or not he made the correct conversion decision. For traders, one of the 
three monitor decisions is selected at random and implemented 14 If the selected monitor chose conversion, then the asset payoff either increases by $\$ 2.00$ per unit (in the case of a value-increasing conversion) or decreases by $\$ 2.00$ per unit (in the case of a value-decreasing conversion).

The fixed-trigger treatment is identical to the above process except that the three monitors are eliminated, and in their place a conversion mechanically occurs whenever the period's median price is less than $\$ 5.00$.

All sessions followed the same general procedures. At the start of each session a cohort of student volunteers (ten or thirteen) was randomly seated at visually isolated personal computers. An experiment administrator then read aloud a common set of instructions, which explained trader and monitor incentives as well as how to make decisions on the computer interface used in the experiment 15 Participants followed along on printed copies of their own, while the administrator read instructions from a version projected onto a wall at the front of the lab. Following the instructions, participants completed a short quiz of understanding, which the experiment administrator reviewed publicly. At any time during the instructions and quiz, participants were encouraged to ask questions by raising their hands. Questions were answered privately 16 Following the quiz, the sessions commenced. The experiment was programmed and conducted with the software z-Tree (Fischbacher 2007).

To facilitate understanding, instructions were presented in parts. Initial instructions were provided for a simple condition in which traders buy and sell asset units in the absence of any possible conversion 17 In this condition, monitors are told the period's median contract price following the close of trade and are asked to guess the underlying market fundamental. After several periods in

\footnotetext{
${ }^{14}$ We used three monitors in each session in order to generate more data points on conversion decisions per session.

${ }^{15}$ Instructions are available in unpublished appendix 1 , available at http://www.ijcb.org.

${ }^{16}$ Quiz responses were not formally recorded. Participants, however, had few questions and seemed comfortable with the instructions.

${ }^{17}$ In DKP, these periods are referred to as the $B A S E$ condition. In the $B A S E$ condition, prices were close to the market fundamental $\theta$, and allocations were very close to fully efficient.
} 
this condition, the session was paused and additional instructions describing a conversion treatment were distributed. An experiment administrator then read aloud these instructions and administered another short quiz of understanding, after which a second segment commenced for ten to fifteen periods. In the second segment, some sessions had value-decreasing conversions and others had valueincreasing conversions. In most sessions, this protocol was repeated in a third segment, which was identical to the second except that the conversion rule was switched to value decreasing (value increasing) 18 Following the conclusion of the final segment, the experiment ended and participants were privately paid and dismissed from the lab.

Participants were upper-level math, science, engineering, and business students enrolled in courses at Virginia Commonwealth University in the spring semesters of 2010 and 2011 (for the previously reported DKP sessions) and the spring semester of 2014 and the fall semester of 2015 (for the new sessions). No one participated in more than one session. Lab earnings were converted to U.S. currency at $\$ 12.00$ lab $=\$ 1.00$ U.S. rate. In U.S. dollars, participant earnings for the $90-120$ minute sessions ranged from $\$ 14.00$ to $\$ 32.25$ and averaged $\$ 23.25$ (inclusive of a $\$ 6.00$ appearance fee).

\subsection{DKP Results}

DKP reports a series of thirty-four market sessions involving 424 participants. Sessions included both regulator and fixed-trigger regimes, under both value-increasing and value-decreasing conversion conditions. Figure 1 summarizes the conversion error results. In each panel of the figure, notice that market fundamentals are clustered into six ranges: the $<\$ 3.00$ and $\geq \$ 7.00$ ranges, where neither triggering mechanism should create price ambiguity, as well as partitions of the $\$ 3.00-\$ 4.99$ and $\$ 5.00-\$ 6.99$ ranges, where, depending on the triggering mechanism and conversion rule, either multiple equilibria or equilibrium non-existence arise in the rational expectations benchmarks. The partitions separate out the ranges $\$ 0.60$ above and below the $\$ 5.00$ efficient conversion limit. Although the

\footnotetext{
${ }^{18} \mathrm{As}$ explained in DKP, in some treatments value-increasing and valuedecreasing regimes were not varied within sessions.
} 


\section{Figure 1. Conversion Error Rates for Regulator (REG) and Fixed-Trigger $(F T)$ Treatments}
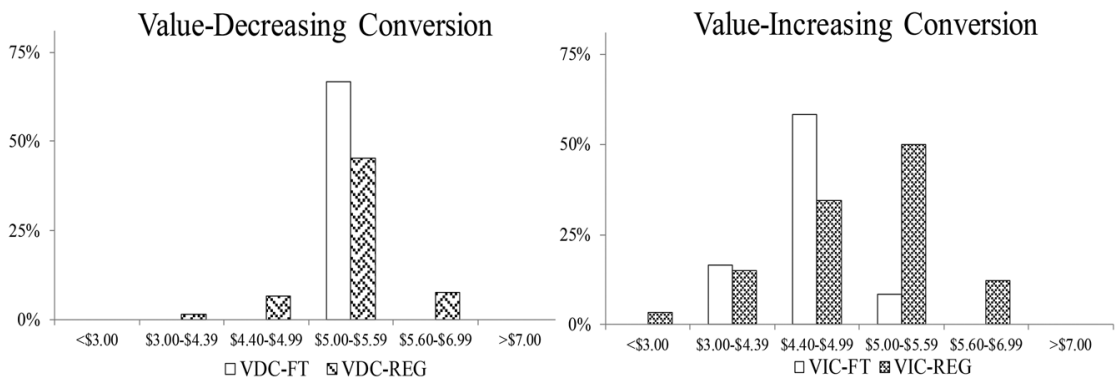

Notes: The horizontal axes list the market fundamentals broken up into different ranges. The vertical axes list the fraction of the time a conversion error is made for fundamentals in each range. A decision to convert when the fundamental is $\geq \$ 5.00$ is counted as an error, as is a decision not to convert when the fundamental is $<\$ 5.00$.

proximity of a market fundamental realization to $\$ 5.00$ is not pertinent in the Bond, Goldstein, and Prescott (2010) or Sundaresan and Wang (2015) models (both of which use a rational expectations framework), it is relevant to the market used in DKP and this paper because they include value heterogeneity in order to generate trade. The $\$ 0.60$ range around the conversion cutoff is used because for market fundamental realizations in this range, some traders must infer from the trading process whether the market fundamental is above or below the $\$ 5.00$ trigger 19

Looking first at the case of value-decreasing conversions, observe that errors occur frequently in the fixed-trigger $(F T)$ regime for fundamental realizations just above the $\$ 5.00$ cutoff, as predicted by the Sundaresan and Wang (2015) analysis. Not consistent with theoretical predictions are the conversion errors under a regulator $(R E G)$ regime. Here again, when market fundamentals were slightly

\footnotetext{
${ }^{19}$ For example, if the market fundamental is $\$ 5.20$, then six traders (with twelve asset units) see a fundamental above $\$ 5.00$, while four other traders (with eight asset units) see a fundamental of $\$ 4.60$. The traders with the low value do not know for sure whether the market fundamental is above $\$ 5.00$ and hence no conversion should occur. A similar situation arises for a fundamental of $\$ 4.80$, except that in this case the high-value traders do not know for sure whether the fundamental is above or below $\$ 5.00$.
} 
above $\$ 5.00$, traders often partially incorporated the value of a conversion into prices and generated median prices in the $\$ 3.00-\$ 4.99$ range. These downward price adjustments yield prices that would not be observed in an equilibrium for the $R E G$ regime -traders should either fully incorporate the value of a conversion, generating market prices of $\$ 2.99$ or less, or realize that the market fundamental exceeds $\$ 5.00$ and no conversion will occur, generating prices of $\$ 5.00$ or more. However, upon seeing these prices, the monitors often errantly concluded that the market fundamental was below $\$ 5.00$ and decided to convert.

In the case of value-increasing conversions, conversion errors tend to cluster around fundamental realizations close to the $\$ 5.00$ cutoff under both triggering mechanisms. However, in the $R E G$ treatment, errors are distributed both above and below the $\$ 5.00$ cutoff, while in the FT treatment, errors cluster in the $\$ 3.00$ to $\$ 4.99$ range. These results are consistent with theoretical predictions: In the $R E G$ regime market, fundamentals of, say, $\$ 4.60$ and $\$ 5.40$ may generate very similar transaction prices, both somewhere in excess of $\$ 5.00$, leaving monitors confused as to the desirability of conversion and roughly as likely to err by converting as by not converting. On the other hand, in the FT regime, conversion errors occur predominantly when the market fundamental is slightly below $\$ 5.00$ and traders are unable to keep the median transaction price below the automatic conversion cutoff.

Combined, these experimental results indicate that the problems of discerning fundamental information from market prices suggested in the theoretical work may frequently lead to conversion errors. Inspecting figure 1 further, however, notice that the relative desirability of the two triggering mechanisms is not obvious.

In the case of a value-decreasing conversion, overall incidence of conversion errors is slightly higher in the FT regime. Perhaps more problematically, the incidence of conversion errors for fundamentals above $\$ 5.00$ was also higher for the FT regime, meaning they were socially undesirable conversions (e.g., type II errors of commission). McDonald (2013) argues that type II errors are likely more problematic than type I errors, so under his criterion these results would make the REG mechanism more appealing. On the other hand, errors occur over a considerably wider range of fundamental realizations in the $R E G$ mechanism. 
In the case of a value-increasing conversion, the overall incidence of errors is roughly the same under either mechanism. Nevertheless, the type of error differs. Under the REG mechanism, the bulk of errors were type II errors of commission, occuring for market fundamentals above $\$ 5.00$. In contrast, under the $F T$ mechanism, errors are concentrated in the ranges of market fundamentals below $\$ 5.00$, meaning that socially desirable conversions failed to occur (type I, errors of omission). Under these criteria, results would make the FT mechanism more appealing.

As discussed in the introduction, a more complete evaluation of the relative desirablity of fixed-trigger and regulator-based triggering mechanisms requires evaluation of regulator behavior in environments enrichened by features that may importantly affect the frequency and accuracy of regulator conversion decisions. The following three subsections describe procedures for treatments that explore the effects of three such environmental alterations on market outcomes: inaction bias, probabilistically supplied non-market information, and the opportunity to delay action.

\subsection{Inaction Bias}

The distortionary effects of external pressures on the timing and magnitude of conversion decisions is potentially an important factor in assessing the value of allowing a regulator to make a conversion decision. There are two distinct reasons to consider introducing bias as a treatment. First, in both the Great Recession and the Savings and Loan Crisis of the 1980s, regulators were criticized for not intervening with sufficient speed. In the Savings and Loan Crisis, in particular, it is well documented that many S\&Ls were insolvent but were allowed to continue to operate in the hope they would recover (White 1991). Introducing a bias toward not acting can be viewed as a more realistic description of regulatory incentives in such contexts. Second, in the previously reported sessions, where the regulator had symmetric preferences over taking actions, undesirable conversions were the most frequent error. This suggests that adjusting the regulator's incentives toward inaction may be a way to reduce these errors.

To assess the effect of a bias against making a conversion decision, we conduct a $R E G B$ treatment, which replicates the $R E G$ 
treatment in DKP, except that we alter monitors' incentives by imposing penalties for an incorrect decision to convert. As in the $R E G$ treatment, monitors were told the median contract price for the periods and then they both guessed the underlying market fundamental and made a conversion decision. As before, they earned a small amount (up to $\$ 3.00$ ) for guessing with sufficient accuracy the market fundamental, and then a larger amount (\$12.00) for making a correct conversion decision (e.g., converting when socially desirable). However, in $R E G B$ they were also punished if they converted when they should not have. In particular, relative to the $R E G$ treatment, payment falls from $\$ 0.00$ to $-\$ 12.00$ if they convert when the fundamental is above $\$ 5.00$. As in the $R E G$ treatment, monitors earn nothing from an error of omission, or a decision to not convert when the fundamental is below $\$ 5.00$. Also as before, after all monitors make decisions, one of their choices is selected at random and implemented in the market (e.g., increasing or decreasing the market fundamental by $\$ 2.00$ in the case conversion is selected). We evaluate both value-increasing and value-decreasing conversions.

In the literature, the commitment problem that encourages inaction is widely regarded as a reason to prefer a fixed-trigger mechanism to a regulator-based mechanism. The analysis in DKP focuses on a different trade-off, namely, how allowing a regulator to react to prices changes the price's informational content. In this respect a bias toward inaction could actually improve performance. As can be seen in figure 1 , for the $R E G$ regime, conversion errors concentrate in the $\$ 5.00-\$ 5.59$ range of fundamentals, as traders incorporate the value of a socially undesirable conversion when the market fundamental is slightly above the $\$ 5.00$ cutoff. A bias toward inaction should make monitors more reluctant to make a decision to convert for the subsequent prices in the $\$ 3.00-\$ 4.99$ range, and in this way reduce the incidence of such type II errors.

In the case of a value-increasing conversion, the effect is unclear. Inaction bias may weaken the willingness of regulators to convert when facing trading prices in the uninformative $\$ 5.00-\$ 6.99$ range. Incentives against action thus may increase the incidence of forgone desirable conversions that generate such uninformative prices (e.g., for market fundamentals in the $\$ 3.00-\$ 4.99$ range), but at the same time they should reduce the incidence of socially undesirable conversions that generate roughly the same prices (e.g., for 
market fundamentals between $\$ 5.00$ and $\$ 6.99)$. Referring back to figure 1, observe that in the value-increasing $R E G$ sessions reported in DKP, the bulk of conversion errors occurred for market fundamentals between $\$ 5.00$ and $\$ 5.59$. Inaction bias would be beneficial on net if it reduces the incidence of these socially undesirable and arguably more costly errors.

\subsection{Non-market Information}

Our second treatment assesses the effects of non-market information. One argument for not adopting a fixed-price trigger is that bank regulators have information about bank quality that is not available to market participants and that information should be used in making decisions. Indeed, Bond, Goldstein, and Prescott (2010) established in their rational expectations model that if the quality of a regulator's signal was sufficiently high, a unique equilibrium exists for a value-increasing conversion, so regulators could learn from market prices. Nevertheless, the quality of a regulator's signal is not always accurate, and the market response to a perception that regulators know the market fundamental may dampen the information transmitted by prices. For this reason, it is worth studying the case in which a regulator has a signal that is not always of sufficient quality to eliminate the equilibrium existence problems found in the theoretical literature.

In this second ( $R E G I)$ treatment, we evaluate the effects of probabilistically providing regulators with accurate non-market information. Procedurally, the REGI treatment is identical to the $R E G$ treatment in DKP except that in addition to being shown the median transactions price after the close of trade each period, there is a 50 percent probability that the monitors are also shown the market fundamental. Traders know the probability that monitors are informed, but they do not know whether the monitor is informed in any particular period. We ran the $R E G I$ treatment under both value-increasing and value-decreasing conversion rules.

\subsection{Action Delay}

Our third treatment ( $R E G D)$ evaluates the capacity of non-market information to endogenously induce an inaction bias 20 Specifically,

\footnotetext{
${ }^{20}$ We are grateful to a referee for suggesting this treatment.
} 
the availability of accurate non-market information via regular but infrequent bank examinations may, in the intervals between examinations, induce regulators to discount or ignore the information conveyed in market prices and delay making conversion decisions.

Procedures for the $R E G D$ treatment parallel those for the $R E G$ treatment with the following differences. Following the close of trade, and after being shown the period's median contract price, the monitor makes a decision to either convert or wait. If the monitor decides to convert, he earns $\$ 12.00$ from a correct decision (e.g., if the market fundamental is less than $\$ 5.00$ ) and $\$ 0.00$ from an incorrect decision. If the monitor decides to wait, he is shown the market fundamental and is then obligated to make the correct conversion decision. In either case, the monitor earns $\$ 6.00$ from a decision to wait 21 We conducted sessions under both value-increasing and value-decreasing conversion rules.

\subsection{Summary}

In total, the new experiment consists of a series of eighteen market sessions, with six sessions conducted in each of $R E G B, R E G I$, and $R E G D$ treatments. Table 1 summarizes the experiment design. In total, 234 undergraduate student volunteers participated in the new experiment. With only minor differences, the previously reported markets were conducted under the same conditions as the sessions reported here.

\section{Experiment Results}

An assessment of the relative merits of the triggering mechanisms in terms of conversion error rates involves comparisons across multiple dimensions. To quantify relative performance differences, we use four criteria. First, and perhaps most obviously, we compare the overall

\footnotetext{
${ }^{21} \mathrm{As}$ in the $R E G$ treatment, monitors also guessed the market fundamental each period and were compensated for the accuracy of their decisions. One additional minor difference from the $R E G$ treatment is that we relaxed the requirement for consistency between the fundamental guess and the conversion decision. In the REGD treatment, a monitor could choose to wait even if he guessed that the fundamental was below $\$ 5.00$. As in the $R E G$ treatment, he could not convert if he guessed that the fundamental exceeded $\$ 5.00$.
} 
Table 1. Experiment Session Structure

\begin{tabular}{|c|c|c|c|c|}
\hline \multirow[b]{2}{*}{ Session } & \multirow{2}{*}{$\begin{array}{l}\text { No. of } \\
\text { Sessions }\end{array}$} & \multicolumn{3}{|c|}{ Session Structure, by Periods } \\
\hline & & $1-2$ & $3-12$ & $13-25$ \\
\hline$R E G B-V I C / R E G B-V D C$ & 3 & $B A S E$ & $R E G B-V I C$ & $R E G B-V D C$ \\
\hline$R E G B-V D C / R E G B-V I C$ & 3 & $B A S E$ & $R E G B-V D C$ & $R E G B-V I C$ \\
\hline$R E G I-V I C / R E G I-V D C$ & 3 & $B A S E$ & $R E G I-V I C$ & $R E G I-V D C$ \\
\hline$R E G I-V D C / R E G I-V I C$ & 3 & $B A S E$ & $R E G I-V D C$ & $R E G I-V I C$ \\
\hline$R E G D-V I C / R E G D-V D C$ & 3 & $B A S E$ & $R E G D-V I C$ & $R E G D-V D C$ \\
\hline$R E G D-V D C / R E G D-V I C$ & 3 & $B A S E$ & $R E G D-V D C$ & $R E G D-V I C$ \\
\hline \multicolumn{5}{|c|}{$\begin{array}{l}\text { Notes: } V D C \text { refers to value-decreasing conversion. } V I C \text { refers to value-increasing } \\
\text { conversion. } B A S E \text { refers to the treatment in which no conversion decision was } \\
\text { allowed. } R E G B \text { refers to the regulatory-inaction-bias treatment. } R E G I \text { refers to the } \\
\text { regulatory-information treatment. } R E G D \text { refers to the regulatory-delay treatment. }\end{array}$} \\
\hline
\end{tabular}

incidence of conversion errors across triggering mechanisms. Second, following McDonald's suggestion that socially undesirable conversions (i.e., errors of commission) are generally more problematic than failures to convert, we evaluate the incidence of conversion errors for market fundamentals of $\$ 5.00$ and above. Third, we consider the extent to which a triggering mechanism facilitates the discovery of the market fundamental via the trading process by evaluating the incidence of conversion errors in the ranges of $\$ 0.60$ below and $\$ 0.60$ above the $\$ 5.00$ efficient-conversion cutoff. Fourth, we consider the extent to which a triggering rule results in "gross" errors, or errors for fundamentals that deviate by more than $\$ 0.60$ from $\$ 5.00$.

A series of simple bivariate linear probability regressions allows evaluation of performance in terms of these four criteria 22 Labeling the six fundamental ranges $<\$ 3.00, \$ 3.00-\$ 4.39, \$ 4.40-\$ 4.99, \$ 5.00-$ $\$ 5.59, \$ 5.60-\$ 6.99$, and $>\$ 7.00$ alphabetically as $a, b, c, d, e$, and $f$, respectively, we estimate the incremental effect of the $R E G$ treatment relative to the $F T$ benchmark. A first regression estimates the incremental effect of the regulator treatment relative to the fixedtrigger rule for all fundamental ranges $a$ though $f$ combined. A

\footnotetext{
${ }^{22}$ We report linear probability estimates for expositional ease. Comparable probit regression estimates, reported in unpublished appendix 2, yield substantially identical results.
} 
second regression assesses the incremental effect of a regulator treatment on the incidence of errors of omission by restricting the set of observations to those where the market fundamental exceeds $\$ 5.00$, or is in the $d, e$, or $f$ ranges. A third regression assesses the incremental effect of the regulator-based triggering mechanism when the market fundamental is close to the $\$ 5.00$ efficient-conversion cutoff by restricting the set of observations to market fundamentals in the $c$ and $d$ ranges. The fourth set of regressions estimates the incremental effect of the regulator-based triggering mechanism on the incidence of gross errors where market fundamentals are in the ranges of below $\$ 4.39$ or above $\$ 5.60$, namely, the $a, b, e$, and $f$ ranges.

Formally, for the set of observations in each value range $j \in\{a b c d e f$, def, $c d$, abef $\}$ we estimate

$$
c e_{i t}=\beta_{0}+\beta_{R E G j} D_{R E G i t}+\mu_{i}+\varepsilon_{i t},
$$

where the dependent variable $c e_{i t}$ takes on a value of 1 if monitor $i$ committed a conversion error in period $t$ and is 0 otherwise, $i \in\{1,2, \ldots$,\# monitors $\}$, and $t \in\{1,2, \ldots$,\# periods $\}$. $D_{R E G i t}$ is an indicator variable that takes on a value of 1 if the regulator treatment is in effect and 0 otherwise. All regressions use the monitor as the unit of observation and model repeated measures on monitors as random effects 23 We further cluster data by session and use a robust (White "sandwich") estimator to control for possible unspecified autocorrelation or heteroskedasticity 24

\subsection{DKP Regulator}

Table 2 summarizes the performance of the $R E G$ sessions relative to those using a fixed-trigger mechanism. Looking at estimates for the

\footnotetext{
${ }^{23}$ In the fixed-trigger sessions, the unit of observation is a market.

${ }^{24}$ In unpublished appendix 3 we follow this same general method to evaluate trading efficiency, which we calculate as the percentage of available gains extracted via the trading process. As is often the case in experiments involving the trade of exogenously valued assets, trader earnings may be quite high even absent any active exchange, because traders may realize a sizable portion of the available earnings by simply holding on to their asset endowment (something participants in fact tend not to do). Our trading efficiency measure more narrowly assesses the extent to which assets flow from low- to high-value holders of assets. Trading efficiency results echo in all respects the conversion-error-frequency results reported in the text.
} 


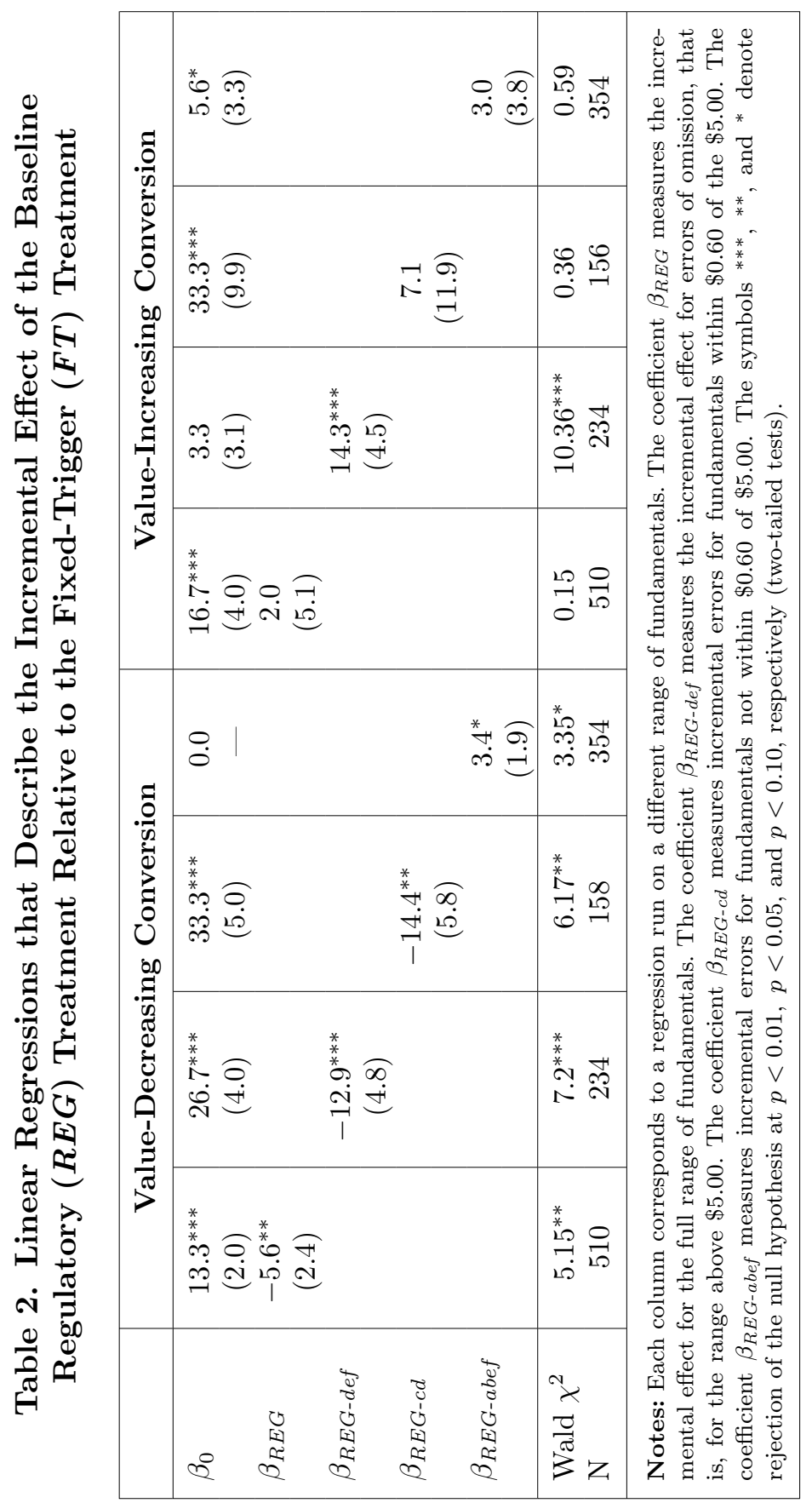


value-decreasing conversion, shown in the left panel, observe that the regulator rule outperforms the fixed trigger on most criteria. The REG markets reduce the overall incidence of conversion errors, $\beta_{R E G}=-5.6 \%(p<0.05)$, and the incidence of type II errors, $\beta_{R E G-\text { def }}=-12.9 \%(p<0.01)$, and help with the discovery of the market fundamental, $\beta_{R E G-c d}=-14.4 \%(p<0.05)$. The regulatorbased trigger does suffer relative to the fixed-trigger rule in the sense that it generates more gross errors, $\beta_{F T \text {-abef }}=3.4 \%(p<0.10)$.

On the other hand, in the case of a value-increasing conversion, the comparison is closer. The small and statistically insignificant coefficient estimate on $\beta_{R E G}$ suggests no overall difference between the fixed-trigger and regulator regimes. The $R E G$ and $F T$ triggering mechanisms are further indistinguishable for realizations close to $\$ 5.00$ and for realizations far from $\$ 5.00$, as indicated by the statistically insignificant coefficient estimates on $\beta_{R E G-c d}$ and $\beta_{F T-a b e f}$, respectively. The baseline $R E G$ markets, however, do raise the incidence of type II errors over the FT markets by 14.3 percent, as indicated by the coefficient estimate on $\beta_{R E G-d e f}(p<0.01)$.

Collectively, these baseline results suggest a sensitivity of the triggering mechanism to the conversion rule. In the case of a valueincreasing conversion, a fixed-trigger mechanism is superior particularly in the sense that it results in significantly fewer type II errors (i.e., socially unnecessary conversions). In the case of a valuedecreasing conversion, the regulator regime generates fewer errors in most respects.

\subsection{Inaction Bias}

Figure 2 plots conversion error rates for the $R E G B$ treatment relative to the counterpart $F T$ treatment. In the graph, we cluster observations into the same six ranges of fundamental realizations reported in figure 1 . Notice in the figure that in the case of a valuedecreasing conversion, the regulator-based rule is clearly superior. As seen in the left panel of figure 2, the $V D C-R E G B$ treatment cuts the incidence of undesirable conversions in the $\$ 5.00-\$ 5.59$ range of fundamental realizations by roughly two-thirds relative to the $V D C$ FT treatment. This reduction in conversion error rates for market fundamentals just above $\$ 5.00$ comes at the cost of some increase in the incidence of forgone socially desirable conversions for market 
Figure 2. Conversion Error Rates for Regulatory-Inaction-Bias $(R E G B)$ and Fixed-Trigger (FT) Treatments

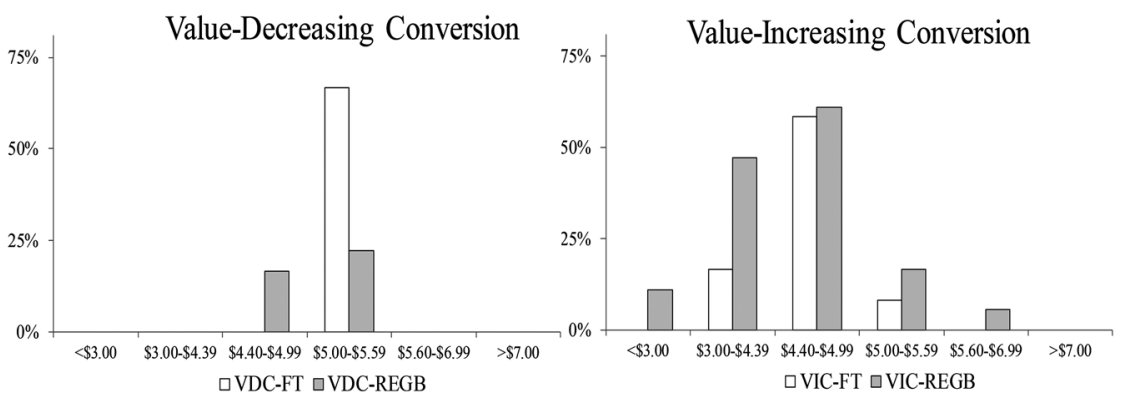

Notes: The horizontal axes list the market fundamentals broken up into different ranges. The vertical axes list the fraction of the time a conversion error is made for fundamentals in each range. A decision to convert when the fundamental is $\geq \$ 5.00$ is counted as an error, as is a decision not to convert when the fundamental is $<\$ 5.00$. In contrast, in the case of a value-decreasing conversion, inaction bias improves the relative performance of a regulator-based triggering rule.

fundamentals in the $\$ 4.40-\$ 4.99$ range. Nevertheless, both the overall incidence of errors and the incidence of errors of commission are considerably lower in the $V D C-R E G B$ treatment than in the $V D C-F T$ treatment.

On the other hand, in the case of value-increasing conversions, inaction bias shifts the incidence of conversion errors from the roughly symmetric dispersion around the $\$ 5.00$ cutoff generated in the VIC-REG treatment to a dispersion more like that in the $V I C-F T$ treatment, with the bulk of errors occurring for market fundamental realizations below $\$ 5.00$ (compare figures 1 and 2) 25 However, the reduction in type II errors of commission in the $V I C$ $R E G B$ treatment does not compensate for the increased incidence of conversion errors for fundamentals below $\$ 5.00$, and relative to the $V I C-F T$ treatment, the $V I C-R E G B$ condition is unreservedly less accurate: For every range of fundamental values over which conversion errors occurred, the incidence of errors is higher in the

\footnotetext{
${ }^{25}$ Unpublished appendix 4 directly compares the $R E G B, R E G I$, and $R E G D$ treatments with the $R E G$ treatment.
} 
$V I C-R E G B$ condition than in the VIC-FT treatment. Thus, in the case of a value-increasing conversion, a fixed-trigger rule yields more desirable results than a monitor who faces pressures to not make a conversion.

Table 3, formatted as table 2, allows a quantitative assessment of the effects of inaction bias by estimating the incremental effects of the $R E G B$ treatment relative to the $F T$ regime. As can be seen in the table, comparison of the REGB and FT treatments is more dependent on the conversion type than was true for the baseline comparisons. In the case of a value-decreasing conversion, inaction bias makes the regulator-based rule a more clearly superior alternative. Incentives inducing inaction eliminate gross errors in a regulator regime (i.e., errors outside the $c$ and $d$ ranges), making the $R E G B-V D C$ and $F T-V D C$ treatments identical in this respect. In the other three dimensions, the regulator regime results in fewer errors overall, $\beta_{R E G B}=-5.6 \%(p<0.10)$, fewer socially undesirable conversions, $\beta_{R E G B \text {-def }}=-17.8(p<0.01)$, and fewer errors when the market fundamental is close to the $\$ 5.00$ cutoff, $\beta_{R E G B-c d}=-13.9(p<0.10)$.

On the other hand, in the case of a value-increasing conversion, the regulator-based regime raises the overall incidence of conversion errors, $\beta_{R E G B}=10.6 \%(p<0.10)$, and the incidence of gross errors, $\beta_{R E G B-a b e f}=13.9(p<0.05)$.

\subsection{Regulatory Information}

In the $R E G I$ treatment, our primary interest regards the indirect market response to monitors probabilistically knowing the underlying fundamental, because the direct effects of such information must necessarily reduce the incidence of conversion errors. We evaluate these indirect effects by examining the incidence of conversion errors in the periods in which the market fundamental was not revealed to monitors. The striped bars in figure 3 illustrate the incidence of conversion errors in these $R E G I^{*}$ periods relative to the $F T$ regime. Looking first at the case of a value-decreasing conversion, errors are confined to the $\$ 5.00-\$ 5.59$ range of fundamentals in the $R E G I^{*}$ periods and roughly parallel the incidence of conversion errors in the FT treatment. The failure of probabilistically providing information to monitors to clarify traders' pricing incentives was a surprise to us, 


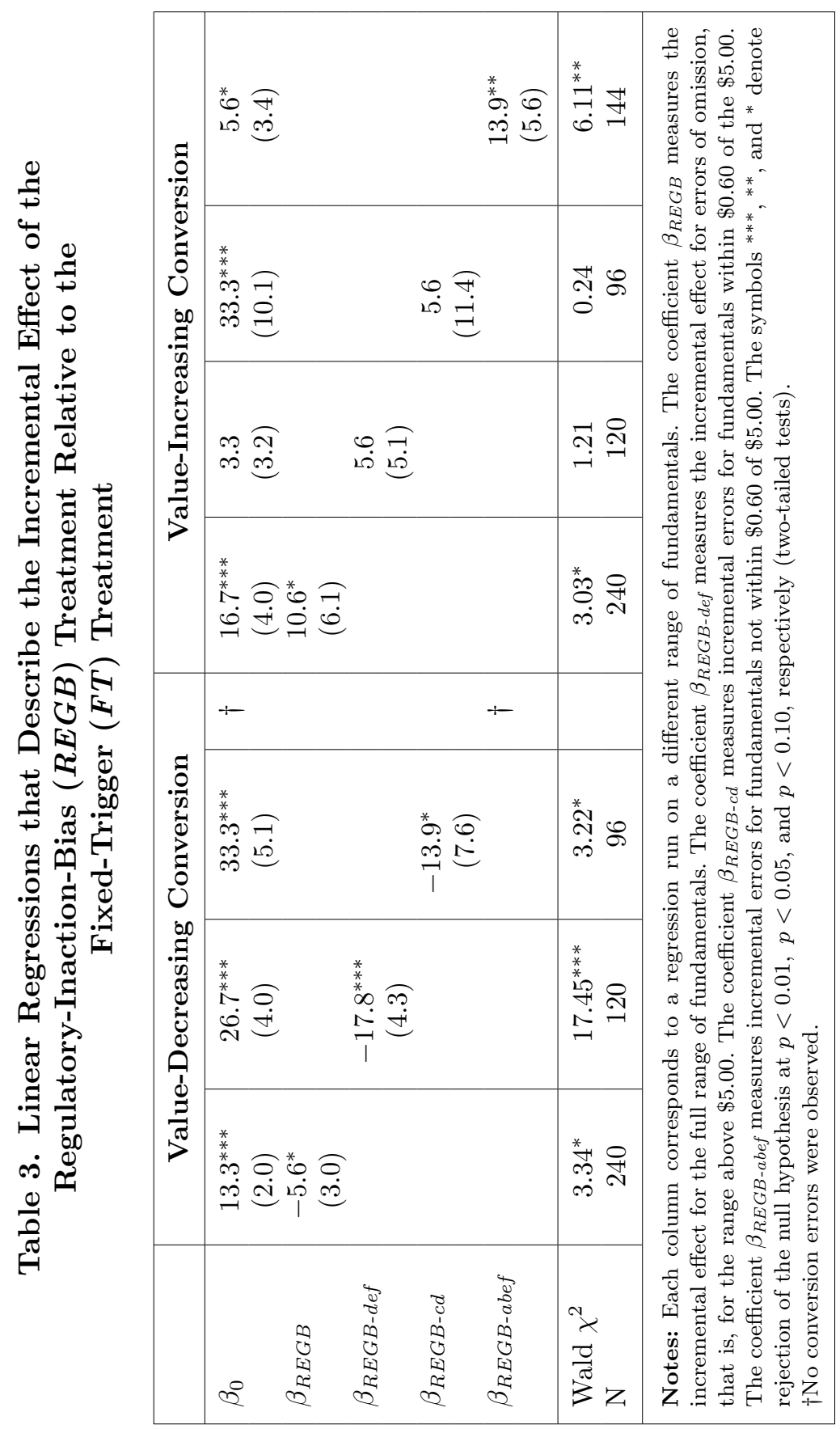




\section{Figure 3. Conversion Error Rates for the Regulatory-Information Treatment Overall (REGI), for Treatment Periods when the Monitor Does Not Observe the Fundamental (REGI*), and for the Fixed-Trigger $(F T)$ Treatment}
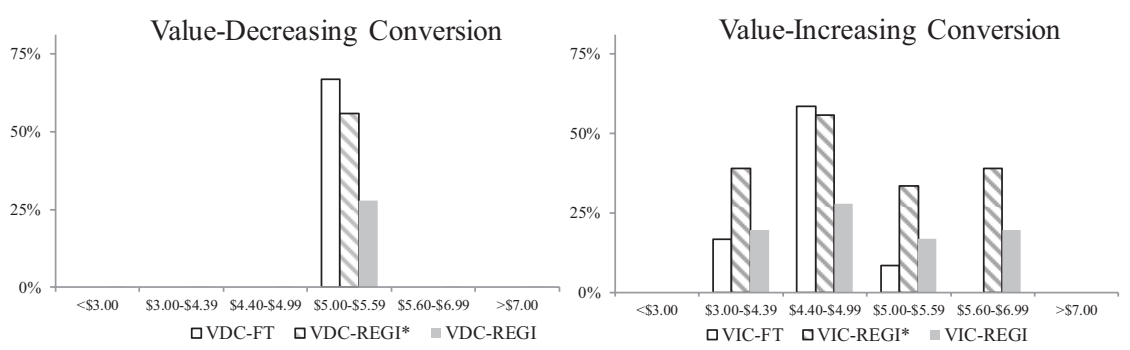

Notes: The horizontal axes list the market fundamentals broken up into different ranges. The vertical axes list the fraction of the time a conversion error is made for fundamentals in each range. A decision to convert when the fundamental is $\geq \$ 5.00$ is counted as an error, as is a decision not to convert when the fundamental is $<\$ 5.00$.

because we expected that the possibility of such information would temper traders' tendencies to pessimistically incorporate the value of a conversion for market fundamentals slightly above $\$ 5.00$. This did not occur to any important extent. Nevertheless, the regulator regime still does slightly better (or at least no worse) than the fixed-trigger regime in the case of a value-decreasing conversion.

In the case of a value-increasing conversion, observe that the market response to monitors possibly knowing the market fundamental significantly undermines the accuracy of a regulator-based trigger mechanism when monitors are not informed. Compared with the $F T$ regime, the incidence of conversion errors in the $R E G I^{*}$ periods is much worse. Except for the $\$ 4.40-\$ 4.99$ range, where conversion error rates for the two treatments are quite similar, conversion errors occur with a markedly higher frequency in the $R E G I^{*}$ periods than in the $F T$ treatment.

The overall incidence of conversion errors in the REGI treatment, illustrated as the solid gray bars in figure 3, combines the beneficial direct effects of informed monitors with the indirect market responses reflected in the $R E G I^{*}$ periods and allows assessment 
of the net effect of probabilistically revealing the market fundamental to monitors. As seen in the left panel of the figure, in the case of a value-decreasing conversion, incorporation of the direct effects of market information on conversion errors makes the regulator in the $R E G I-V D C$ treatment unquestionably superior to the $F T-V D C$ counterpart.

In the case of a value-increasing conversion, however, the direct effects of informed monitors, which scale down the overall incidence of conversion errors, are offset by the increased range of fundamentals for which conversion errors occur. Thus, while the overall incidence of errors in the $R E G I-V I C$ treatment is not noticeably higher than in the FT-VIC counterpart, the increased dispersion in errors causes monitors in the REGI-VIC treatment to both err more frequently when the market fundamental is not close to the $\$ 5.00$ cutoff and commit more type II errors of commission (socially undesirable conversions).

The estimates of incremental effects reported in tables $4 \mathrm{~A}$ and $4 \mathrm{~B}$ provide a quantitative evaluation of the effects of probabilistically revealing the market fundamental to monitors. Table $4 \mathrm{~A}$ summarizes indirect effects by estimating incremental error rates in the uninformed $R E G I^{*}$ periods relative to the $F T$ regime. As shown on the left side of table $4 \mathrm{~A}$, in the case of a value-decreasing conversion, the accuracy of a regulator in the $R E G I^{*}$ periods is statistically indistinguishable from a fixed-trigger rule in all dimensions. In stark contrast, in the case of a value-increasing conversion, the indirect effects of probabilistically informed monitors unquestionably weakens a regulator-based triggering rule relative to a fixed-trigger mechanism. Over the four dimensions we evaluate, the regulator makes between 11.1 percent and 23.6 percent more errors in the $R E G I^{*}$ periods than does a fixed trigger, with the differences significant at $p<0.01$ in all dimensions but one.

Table 4B summarizes the incremental effect of the REGI treatment relative to the fixed-trigger mechanism. For the valuedecreasing conversion, the regulator mechanism performed significantly better under the $R E G I$ treatment than under the fixed-trigger treatment. There was a reduced overall rate of conversion errors, $\beta_{R E G I}=-7.8 \%(p<0.01)$, a lower incidence of socially undesirable conversions, $\beta_{R E G I-d e f}=-15.6 \%(p<0.01)$, and a lower incidence of "close" errors, $\beta_{R E G I-c d}=-19.4 \%(p<0.01)$. 


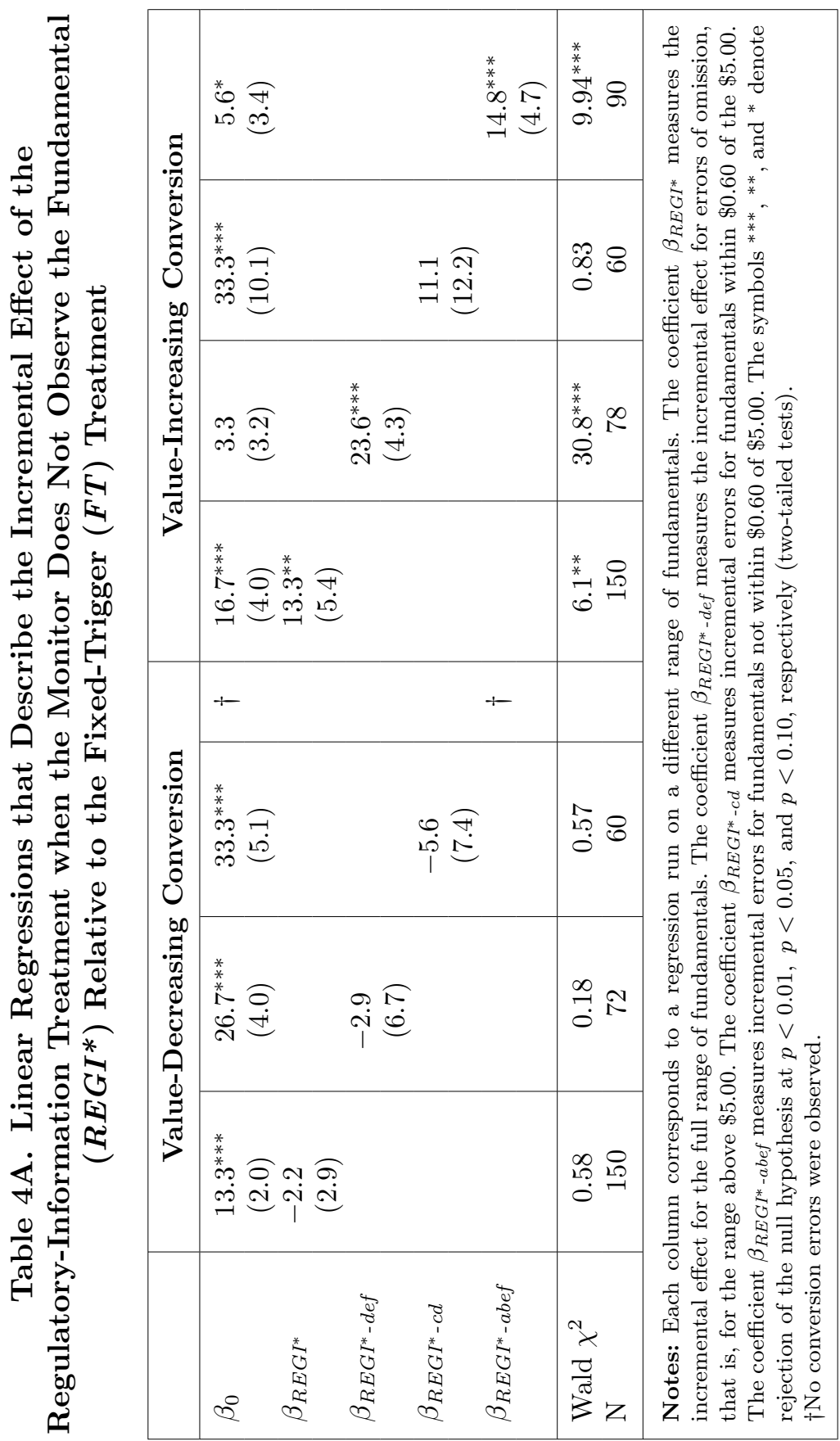




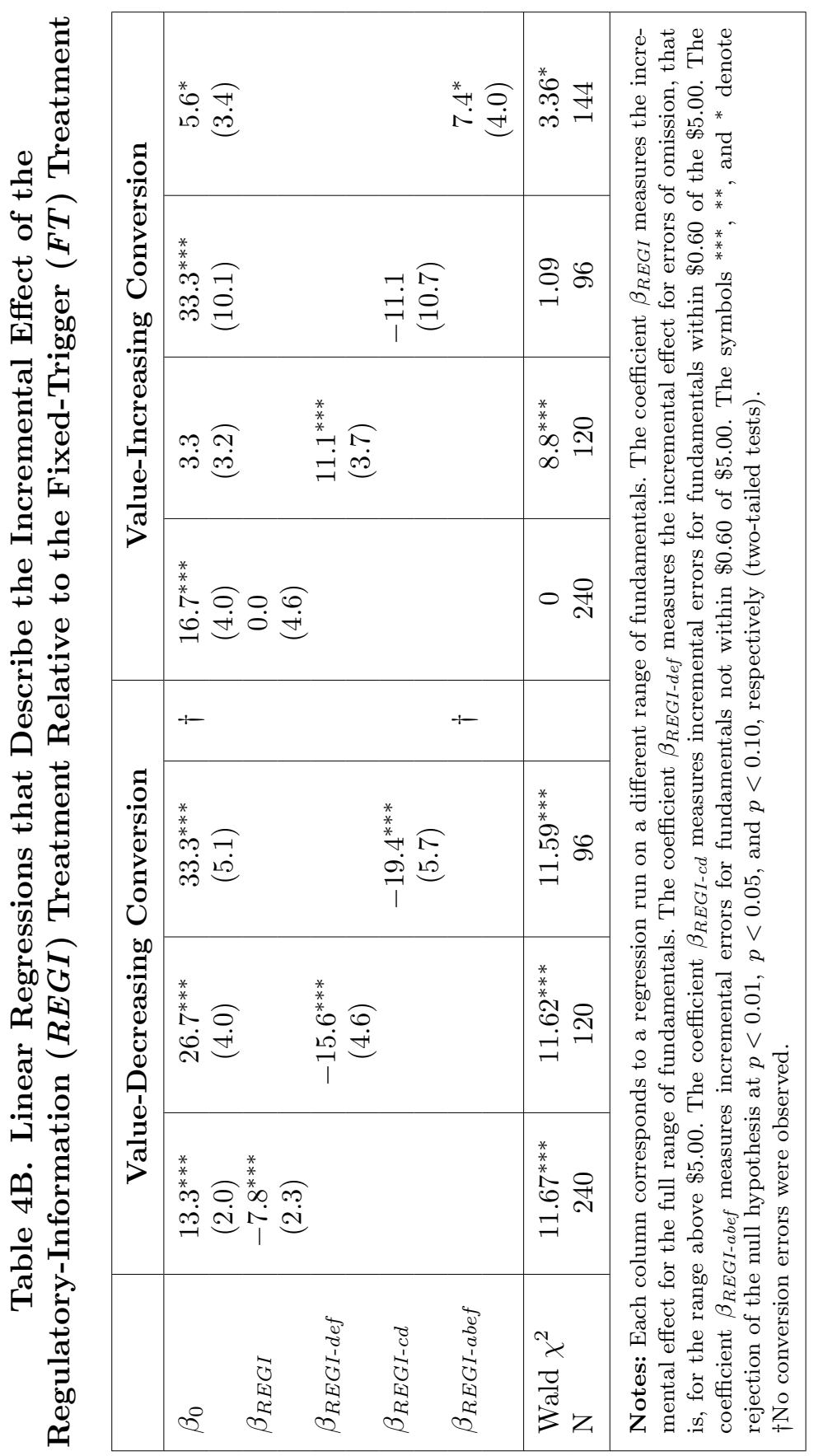


Remarkably, for the value-increasing conversion, the fixed-trigger mechanism performs better than REGI treatment despite the monitors' better information. There are significantly higher incidences of socially undesirable conversions $\left(\beta_{R E G I-d e f}=11.1 \%, p<0.01\right)$ and gross errors $\left(\beta_{R E G I-a b e f}=7.4 \%, p<0.10\right)$ in $R E G I$ than in the fixed-trigger treatment. The desultory effects of better information on the accuracy of conversion decisions is noteworthy: The possibility of monitors knowing the underlying fundamental reduces the informational content of prices, as traders, now less reluctant to incorporate the value of a conversion into their trading prices, generate prices in the ambiguous $\$ 5.00-\$ 6.99$ range with an increased frequency 26

\subsection{Optional Regulatory Delay}

Finally, consider the conversion error rates for the $R E G D$ treatment relative to the $F T$ treatment. Here, we count as a conversion error the decision to wait if the fundamental is below $\$ 5.00$, along with the decision to convert if the fundamental is above $\$ 5.00$. Figure 4 illustrates the incidence of conversion errors in the $R E G D$ treatment relative to the $F T$ treatment.

In the case of a value-decreasing conversion, shown in the left panel of figure 4, notice that the incidence of conversion errors for fundamental realizations above $\$ 5.00$ in the $R E G D$ treatment is about two-thirds of that for the FT regime. For this reason, the presence of a monitor results in somewhat fewer errors of "commission" (although the improvement is smaller than observed in the REGB and REGI treatments). Nevertheless, in the case of a value-decreasing conversion, the REGD treatment does not obviously reduce the overall level of conversion errors relative to the $F T$ regime. In fact, in the case of a value-decreasing conversion, the overall incidence of conversion errors closely parallels the levels observed in the $R E G I^{*}$ periods of the probabilistic information treatment in which monitors did not know the market fundamental prior to making conversion decisions.

\footnotetext{
${ }^{26}$ For example, for fundamentals in the $\$ 4.40-\$ 4.99$ range, mean price deviations from the ex post efficient level are much smaller in the $R E G I$ treatment than in either the FT or the REG treatments, as can be seen in figure A3.1 of unpublished appendix 3.
} 


\section{Figure 4. Conversion Error Rates for the Regulatory-Delay (REGD) and Fixed-Trigger $(F T)$ Treatments}

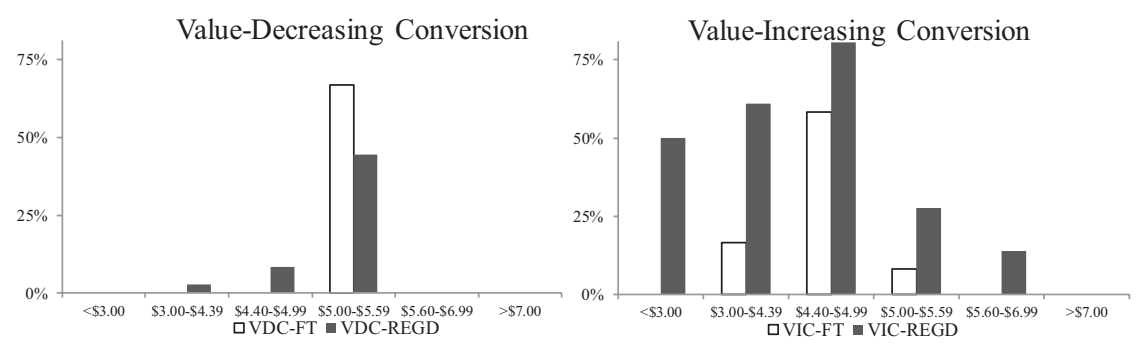

Notes: The horizontal axes list the market fundamentals broken up into different ranges. The vertical axes list the fraction of the time a conversion error is made for fundamentals in each range. A decision to convert when the fundamental is $\geq \$ 5.00$ is counted as an error, as is a decision to wait when the fundamental is $<\$ 5.00$.

On the other hand, as shown in the right panel of figure 4, in the case of a value-increasing conversion, allowing the monitor to delay acting until the arrival of additional information results in a uniformly higher incidence of conversion errors for every range of fundamental realizations. Particularly noticeable is the spectacularly high incidence of conversion errors in the $R E G D$ treatment for fundamental realizations below $\$ 5.00$. Error rates are over 80 percent in the $\$ 4.40-\$ 4.99$ range and reach 50 percent even for fundamentals below $\$ 3.00$. The high rate of conversion errors for fundamentals below $\$ 3.00$ is particularly remarkable. Not only do the monitors defer action when prices fail to clearly convey accurate information regarding whether conversion is warranted, but surprisingly, they also defer acting even when prices clearly indicate that the fundamental is below $\$ 5.00$. Of course, the cost to monitors of this conversion error is smaller than in the earlier treatments because the monitors still receive $\$ 6.00$ if they wait, so that explains some of this high error rate. Overall, it appears that some monitors frequently choose to wait rather than make the effort and take the risk of making a decision.

Table 5 summarizes the incremental effects of the regulator-based rule relative to the fixed-trigger mechanism when the regulator has 


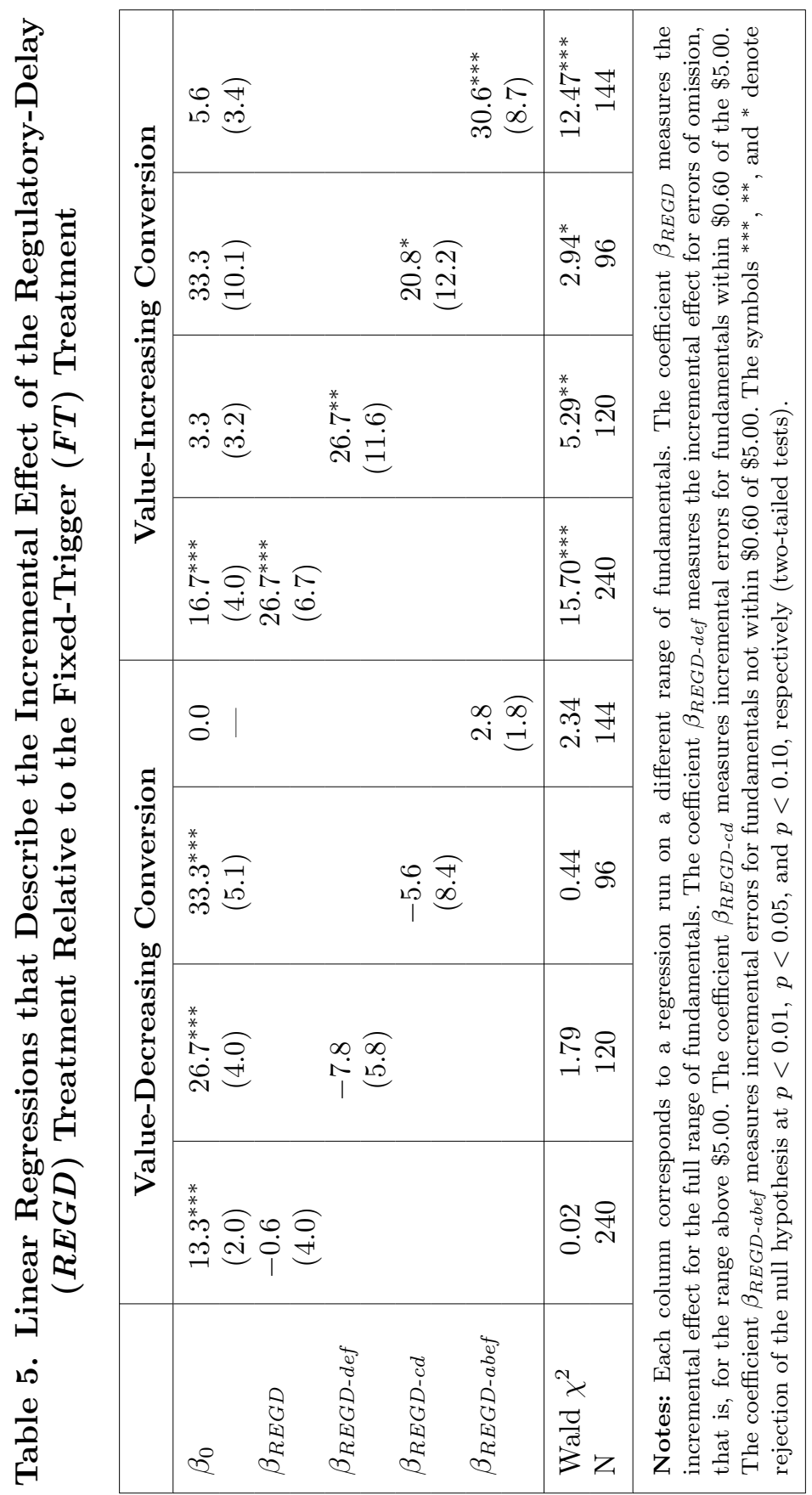


the option to wait for the arrival of fully accurate non-market information. As can be seen in the left panel of table 5, in the case of a value-decreasing conversion, the combination of non-market information and an endogenously induced inaction bias does not exert any significant effects. Although the REGD treatment in this case generates fewer errors than the $F T$ treatment in every dimension except one (the incidence of gross errors, $\beta_{R E G I-a b e f}=2.8$ ), none of the differences differ from zero at conventionally accepted significance levels 27

In contrast, in the case of a value-increasing conversion, the $R E G D$ treatment generates both sizably and significantly more conversion errors than the $F T$ treatment by every measure, as can be seen by the large and uniformly positive coefficients in the right side of table 5 . In fact, in the case of a value-increasing conversion, this inaction bias endogenously induced by the future availability of non-market information generates significantly higher conversion error rates than either inaction bias or the probabilistic availability of non-market information 28

As discussed earlier, in this treatment we count as a conversion error a decision to wait when conversion is socially desirable, even though conversion ultimately occurs with a delay. For this reason, the opportunity costs of inaction are lower than in the $R E G B$ treatment and, unlike the $R E G I$ treatment, regulators always have access to non-market information (although they must always make a wait/convert decision prior to seeing the fundamental).

The consequences of allowing monitors to delay action suggest two comments. First, the possibility of waiting for further information translated into a strong desire to wait, particularly when the prices were not fully revealing. These results provide one reason for why regulators may sometimes wait to act in practice.

\footnotetext{
${ }^{27}$ Note however, that a prior expectation that the delay treatment would result in reduced errors (e.g., using a one-tailed test) allows rejection of the null that $\beta_{R E G D-d e f}=0$ at $p<0.09$.

${ }^{28}$ For the case of a value-increasing conversion, the $R E G D$ treatment yields significantly higher conversion error rates in every dimension than either the $R E G B$ or the $R E G I$ treatment, with the exception of an insignificant difference in the incidence of errors of commission with respect to the REGI treatment. Even this single insignificant difference is fairly large $\left(\beta_{R E G D \mid I-d e f}=15.6, p<0.17\right)$. Results appear in tables A4.5 and A4.6 of unpublished appendix 4.
} 
Second, in the case of a value-decreasing conversion, the opportunity to wait fails to further enhance the performance of the regulator relative to the $R E G B$ and $R E G I$ regimes. Price deviations for the $R E G D$ and $R E G I$ treatment (not shown) are again similar in each case, but unlike the REGI treatment, monitors in the REGD treatment must uniformly make wait/convert decisions prior to seeing the fundamental 29

By way of contrast, in the case of a value-increasing conversion, the performance of a regulator in the $R E G D$ regime is worse than in the other treatments. Not only does the opportunity to delay action induce traders to more fully incorporate the value of a conversion into prices (as in the REGI regime), but the opportunity to receive fundamental information following a delay induces some monitors to ignore the informational content of prices altogether 30

\subsection{Summary of Results}

Table 6 provides an overall summary of results. Each row of the table summarizes instances in which conversion error rates differed significantly across the regulator and fixed-trigger regimes, where significance means $p<0.10$ (two-tailed test). Capitalized entries $\mathrm{R}$ or $\mathrm{F}$ indicate a large difference, where the error rate for the regulator (fixed-trigger) regime exceeds that for the fixed-trigger (regulator) regime by at least 10 percentage points. Lowercase entries $\mathrm{r}$ or $\mathrm{f}$

\footnotetext{
${ }^{29}$ In the case of a value-decreasing conversion, the $R E G D$ treatment generates significantly more errors of commission than either the REGB or the REGI treatments, as can be seen in tables A4.5 and A4.6 of unpublished appendix 4. In this case, the incidence of conversion errors for the $R E G D$ treatment is statistically indistinguishable from that in the $R E G I^{*}$ periods, as shown in table A4.7. In general, errors of commission occur in the value-decreasing case, as traders pessimistically incorporate the value of a conversion into prices when the fundamental is close to $\$ 5.00$. The possibility of non-market information tends to make traders more pessimistic than inaction bias. Unlike the REGI treatment, however, monitors never see the underlying fundamental prior to making a conversion decision, and hence generate outcomes like those in the $R E G I^{*}$ periods.

${ }^{30}$ Figure A3.1 in unpublished appendix 3 illustrates the similarity of price deviations in the $R E G I$ and $R E G D$ regimes for case of a value-increasing conversion. The additional tendency of some monitors to ignore the informational content of prices altogether in the $R E G D$ regime can be formally seen in table A4.7 of unpublished appendix 4. Here, the overall incidence of conversion errors in the $R E G D$ treatment significantly exceeds that in the $R E G I^{*}$ periods because of a higher incidence of gross errors.
} 


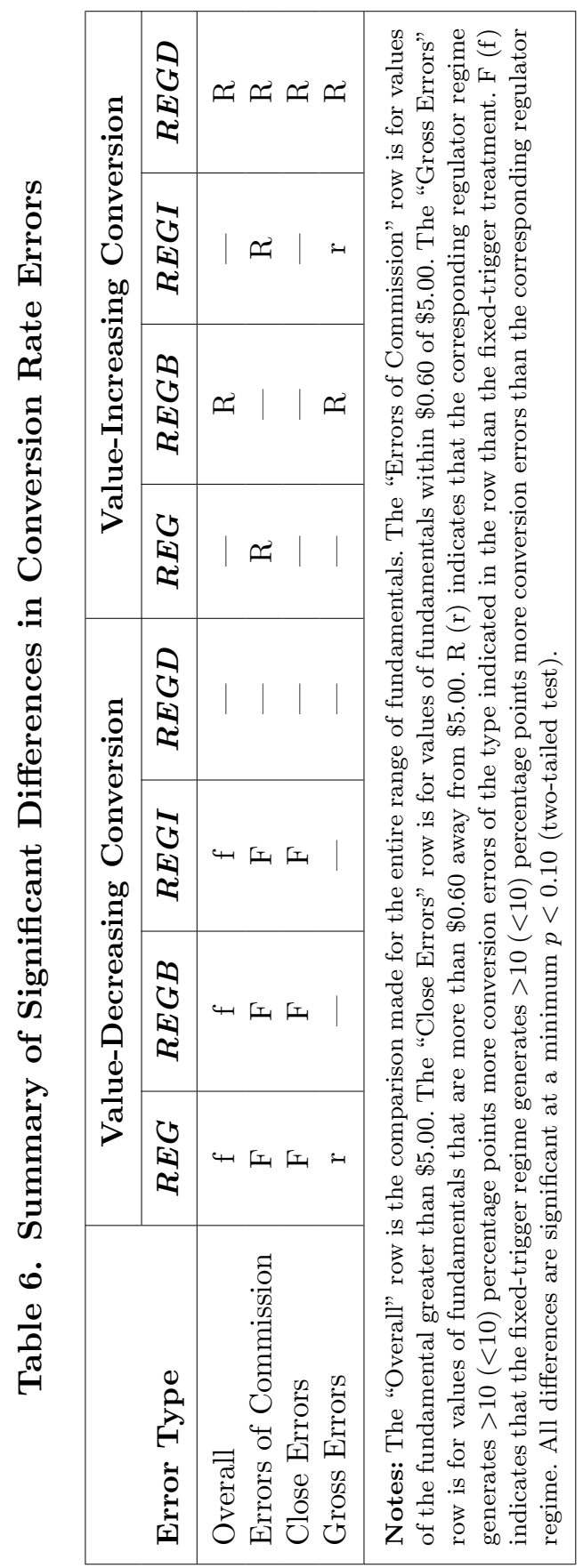


indicate smaller but still significant differences in conversion error rates. In the value-decreasing regime, shown in the left panel, the fixed-trigger rule usually generates a higher rate of conversion errors, although none of these differences persist in the $R E G D$ treatment. In contrast, for the value-increasing conversion case, shown in the right panel, the regulator regime usually yields more conversion errors. Differences tend to be large, and in the $R E G D$ treatment, they are large in every range.

\section{Conclusion}

CoCos have justifiably received a great deal of attention as a way to improve the stability of systemically significant financial institutions. An important unresolved issue regarding the implementation of CoCo bonds regards the selection of a triggering mechanism. Many academic proposals suggest use of a mechanistic fixed-triggering mechanism, which provides increased certainty regarding the timing and magnitude of a conversion relative to a regulator-based mechanism, and is less susceptible to manipulation. In practice, however, the triggering condition for many CoCo issues includes regulatory discretion. Theoretical analysis provides no clear guidance as to which type of mechanism is preferable. Furthermore, due to their novelty, no naturally occurring evidence exists to guide policymakers in their mechanism choice.

Our experimental results indicate that the relative superiority of mechanistic fixed-trigger and regulator-based triggering mechanisms depends on the conversion rule. In the case of a value-decreasing conversion, the regulator-based mechanism performs better in many of the cases, but not all of them. In particular, it is no better than the fixed-trigger mechanism in the regulatory-delay regime. In the case of a value-increasing conversion, a fixed-trigger mechanism robustly outperforms a regulator-based mechanism.

The usually better performance of the regulator regime under value-decreasing conversion is of interest because many policy proposals advocate for a fixed-trigger mechanism. However, it is important to note that the basis for this recommendation is often to prevent forbearance by supervisors, that is, to prevent supervisors not acting when a bank is in trouble because they fear political repercussions. Our experiment addresses a different regulatory decision issue, 
namely, whether regulators can effectively use information in prices to make decisions when the market takes that into account. Consequently, our results should not be viewed as a critique of forbearance arguments.

Nevertheless, our results do illuminate an aspect of decision making that is related to forbearance and to our knowledge has not been considered in the bank regulation literature. In our regulatory-delay treatment, we found that knowing that better information would arrive in the future made the monitors reluctant to act. This type of behavior looks like forbearance even though the motivations may well be different than those driving regulatory behavior during past banking crises.

Another result of interest was the perverse effect of giving the regulator more information in the REGI and REGD treatments. Improving a regulator's information or access to information does not necessarily improve the accuracy of conversion decisions. Here, apparently, if a regulator either may know or may have access to the underlying fundamental, the market acts as if the regulator in fact knows it, which is fine if the regulator actually has either good information or easy access to that information. But in states where the regulator is uninformed, prices convey even less useful information to the regulator. This result can be viewed as a variation on results in information economics, where more information is not necessarily better for welfare.

Contingent capital and the related idea of bail-in debt require an effective trigger if conversions are to be made before a bank reaches insolvency. The experiment reported in this paper indicates that the effectiveness of mechanisms that depend on price depend on the details of the conversion as well as the information and choices that a regulator has.

More generally, our experiment suggests that experimental methods can be a useful tool for evaluating mechanisms designed to improve the capital structure of a bank, prior to implementing them in practice. The results reported here identified ways in which the trigger design affects the frequency of conversion errors. If pricebased triggers were to become closer to implementation, then it would be useful to know to what degree the forces we identified here vary with parameters such as the amount of delay or the asymmetry of regulatory incentives. Investigating these questions would require 
additional experiments with different parameterizations. Similarly, it may be desirable to evaluate the effects of other features of banking such as actions of other banks or the ability of a bank to influence its fundamental. Again, additional experimentation using variants of our design could also help answer these questions.

\section{References}

Avdjiev, S., P. Bolton, W. Jiang, A. Kartasheva, and B. Bogdanova. 2015. "CoCo Bond Issuance and Bank Funding Costs." Manuscript, Columbia Business School.

Balla, E., E. Prescott, and J. Walter. 2015. "Did the Financial Reforms of the Early 1990s Fail? A Comparison of Bank Failures and FDIC Losses in the 1986-92 and 2007-13 Periods." Working Paper No 15-05, Federal Reserve Bank of Richmond.

Berger, A., and S. Davies. 1998. "The Information Content of Bank Examinations." Journal of Financial Services Research 14 (2): 117-45.

Berger, A., S. Davies, and M. Flannery. 2000. "Comparing Market and Regulatory Assessments of Bank Performance: Who Knows What When?" Journal of Money, Credit and Banking 32 (3): 641-67.

Birchler, U., and M. Facchinetti. 2007. "Self-Destroying Prophecies? The Endogeneity Pitfall in Using Market Signals for Prompt Corrective Action." Manuscript, University of Zurich.

Bond, P., I. Goldstein, and E. Prescott. 2010. "Market-Based Corrective Actions." Review of Financial Studies 23 (2): 781-820.

Calomiris, C., and R. Herring. 2012. "Why and How to Design a Contingent Convertible Debt Requirement." In Rocky Times: New Perspectives on Financial Stability, ed. Y. Fuchita, R. J. Herring, and R. E. Litan (chapter 5). Washington: Brookings/NICMR Press.

- 2013. "How to Design a Contingent Convertible Debt Requirement That Helps Solve Our Too-Big-to-Fail Problem." Journal of Applied Corporate Finance 25 (2): 39-62.

Davis, D., O. Korenok, and E. Prescott. 2014. "An Experimental Analysis of Contingent Capital with Market-Price Triggers." Journal of Money, Credit and Banking 46 (5): 999-1032. 
DeYoung, R., M. Flannery, W. Lang, and S. Sorescu. 2001. "The Information Content of Bank Exam Ratings and Subordinated Debt Prices." Journal of Money, Credit and Banking 33 (4): 900-925.

Feldman, R., and J. Schmidt. 2003. "Supervisory Use of Market Data in the Federal Reserve System." Manuscript, Federal Reserve Bank of Minneapolis.

Fischbacher, U. 2007. "z-Tree: Zurich Toolbox for Ready-made Economic Experiments." Experimental Economics 10 (2): 171-78.

Flannery, M. 1998. "Using Market Information in Prudential Bank Supervision: A Review of the U.S. Empirical Evidence." Journal of Money, Credit and Banking 30 (3): 273-305.

- 2009. "Stabilizing Large Financial Institutions with Contingent Capital Certificates." Manuscript, University of Florida.

Hayden, E. 2014. "Coco Helping Investors Sleep?" Economia (Institute of Chartered Accountants in England and Wales, ICAEW) April 11.

McDonald, R. 2013. "Contingent Capital with a Dual Price Trigger." Journal of Financial Stability 9 (2): 230-41.

Pennacchi, G. 2011. "A Structural Model of Contingent Bank Capital." Manuscript, University of Illinois.

Pennacchi, G., T. Vermaelen, and C. Wolff. 2013. "Contingent Capital: The Case for COERCs." Manuscript, University of Illinois.

Prescott, E. 2012. "Contingent Capital: The Trigger Problem." Economic Quarterly (Federal Reserve Bank of Richmond) 98 (1): $33-50$.

Raviv, A. 2004. "Bank Stability and Market Discipline: Debtfor-Equity Swap versus Subordinated Notes." Available at http://EconPapers.repec.org/RePEc:wpa:wuwpfi:0408003.

Roll, R. 1984. "Orange Juice and Weather." American Economic Review 74 (5): 861-80.

Siemroth, C. 2015. "The Informational Content of Prices when Policy Makers React to Financial Markets." Manuscript, University of Mannheim (November 14).

Sundaresan, S., and Z. Wang. 2015. "On the Design of Contingent Capital with a Market Trigger." Journal of Finance 70 (2): 881-920.

White, L. 1991. The SESL Debacle. New York: Oxford University Press. 